\title{
STAR WARS \\ ¿UNA SAGA ANTICAPITALISTA?
}

Star Wars, an Anti-capitalist Capitalistic Saga?

\section{RESUMEN}

Durante las movilizaciones sociales que se desarrollaron en Chile, Colombia y muchos otros países del mundo antes y después del mes de diciembre de 2019, los y las participantes ostentaron nuevos símbolos de lucha que podrían ser interpretados como un giro en los imaginarios políticos. Entre esas imágenes poderosas, en lugar de la hoz y el martillo, es preciso destacar varias referencias a una cultura popular globalizada que la juventud supo recuperar, desviar o trascender - por ejemplo: El Joker, V de Vendetta, La Casa de Papel y, como no, Star Wars-. Al tomar en cuenta el imperio económico que representa la saga creada por George Lucas en 1977 y, manejada desde 2012 por la Walt Disney Company, puede parecer paradójico pregonar que esta galaxia no muy lejana sea un canto de guerra en contra del capitalismo contemporáneo. Sin embargo, en los libros, las historietas o los videojuegos que se agregan al universo bien conocido de las películas, podemos encontrar las bases de un verdadero pensamiento crítico que pone en tela de juicio las relaciones de dominación, explotación, exclusión o desigualdad que caracterizan el modelo de sociedad rechazado por los y las manifestantes de la Plaza Italia, hoy Plaza de la Dignidad, en Santiago de Chile y en tantas otras partes de nuestro planeta.

Palabras claves: Star Wars, capitalismo, explotación, resistencia ciudadana, \#chiledespertó

\section{UNIVERSUM}

Revista de Humanidades y Ciencias Sociales

\begin{abstract}
ALAIN MUSSET
Escuela de Altos Estudios en Ciencias Sociales de París (EHESS), Paris, Francia.

Correo electrónico:

musset@ehess.fr

ORCID: 0000-0003-2509-0245

ResearchGate: Alain Musset

Scholar.google:

Academia.edu: AlainMusset

Este texto, del cual una primera versión en francés ha sido publicada en 2017 por la revista digital Divergences2, está basado en la conferencia del mismo nombre que el autor dictó el 10 de octubre de 2019 en la Biblioteca Nacional de Chile (Santiago) con el propósito de presentar su libro Star Wars, un estudio urbano-galáctico, publicado por la Editorial Bifurcaciones (2018).
\end{abstract}




\begin{abstract}
During the social mobilizations that took place in Chile, Colombia and many other countries in the world before and after December 2019, the participants displayed new symbols of struggle that could be interpreted as a shift in political imagery. Among these powerful images, instead of the hammer and sickle, it is necessary to highlight several references to a globalized popular culture that the youth were able to recover, divert or transcend - for example The Joker, V for Vendetta, La Casa de Papel, and, of course, Star Wars - . Taking into account the economic empire represented by the saga created by George Lucas in 1977 and managed since 2012 by the Walt Disney Company, it may seem paradoxical to proclaim that this galaxy not far away is a war song against contemporary capitalism. However, in the books, comics or video games that are added to the well-known universe of the movies, we can find the basis of a true critical thought that questions the relationships of domination, exploitation, exclusion or inequality that characterize the model of society rejected by the demonstrators of Plaza Italia, today Plaza de la Dignidad, in Santiago de Chile, and in so many other parts of our planet.
\end{abstract}

Keywords: Star Wars, capitalism, exploitation, citizen resistance, \#chiledespertó

Pregonar que Star Wars es un libelo anticapitalista ${ }^{1}$ y que Luke Skywalker es una especie de Che Guevara intergaláctico puede parecer a la vez paradójico y provocador. Si el Rico McPato (uncle Scrooge en inglés) desembolsó en 2012 la módica suma de cuatro mil millones de dólares para

1 El objetivo de este texto no es de analizar o poner en tela de juicio palabras claves de tipo "capitalismo", "neoliberalismo", "explotación", "dominación", "desigualdad", "injusticia", entre otras. De cierta forma, tal como aparecen en las movilizaciones sociales que han conmovido no solamente Chile, sino también Colombia y muchos otros países antes y después del 18 de octubre de 2019, ya no son nociones, sino eslóganes —o sea instrumentos de lucha que rebasan los marcos teóricos (a veces contradictorios) - diseñados por el mundo académico. Sin embargo, en caso de emergencia, los lectores y las lectoras podrán referirse a los libros de Thomas Piketty: El capital en el siglo XXI y Capital e ideología. 
recomprar la franquicia (y recuperar los derechos de Indiana Jones en el proceso), es sin lugar a duda porque la inversión era rentable. Es cierto que las cifras hablan por sí solas: entre 1977 y 2016 los ingresos totales acumulados ya excedían los treinta mil millones de dólares (entre la boletería y el merchandising). Debemos agregar que Rogue One, lanzado en las pantallas en diciembre de 2016, trajo más de mil millones de dólares al Club Mickey, The Last Jedi 1.332 millones y The Force Awakens más de 2.000 millones. El relativo fracaso de Solo, A Star Wars Story (menos de 400 millones de dólares) y las críticas al Episodio VIII formuladas por una gran parte de los y las fanáticas han impactado severamente el programa de lanzamiento de nuevas películas, pero The Rise of Skywalker ha regalado a la Walt Disney Company nuevos ingresos jugosos — sin hablar de las oportunidades abiertas por el éxito de la serie The Mandalorian que solo se puede ver en la plataforma de la compañía-. ${ }^{2}$

Star Wars es en sí misma un imperio financiero abrumador. No solo se trata de películas, sino también de un sin fin de subproductos: juguetes, réplicas, ropa (desde chaquetas y playeras hasta calcetines y calzoncillos), videojuegos, CD, DVD, novelas, cómics, series de televisión, platos, vasos, cubiertos, calendarios, caramelos, bebidas... Los y las fans suelen competir entre sí para encontrar a los actores y actrices que jugaron un papel mínimo en un episodio de la saga. Resulta difícil pagar menos de veinte euros por el autógrafo de un simple comparsa y los precios se disparatan cuando se trata de una gran figura como Anthony Daniels, el actor que, desde 1977, encarna al personaje icónico de C-3PO, el robot de protocolo creado por el joven Anakin Skywalker, este lindo niño que más tarde se convertiría en el infame Darth Vader. En su deseo de cumplir con sus deberes académicos, el autor (cuyo alias en Planeta Star Wars ${ }^{3}$ es Darkalain) nunca dudó en involucrarse personalmente en todas las actividades relacionadas con el universo creado

2 Entre muchas fuentes sugiero revisar: The Numbers en Data and the Movie Business Meet. (2019, December 20). Box Office History for Star Wars Movies. https://bit.ly/304rsDfhttps:// bit.ly/3g36Ro9

3 Planète Star Wars. (2020, March 30).Le fan club Star Wars. https://bit.ly/3g36Ro9 
por George Lucas, siguiendo de maneja muy relajada el método antropológico conocido bajo el nombre de "observación participante" (figuras 1 y 2).

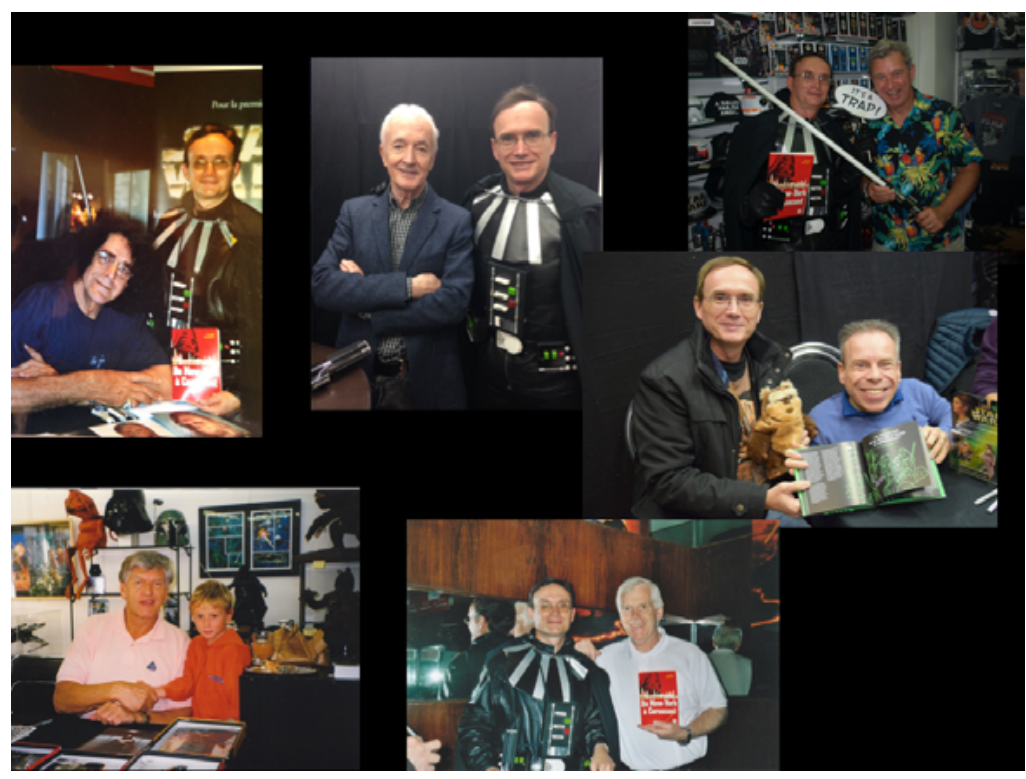

Figura 1. Encuentros del autor y su hijo con unos actores: Peter Mayhew (Chewbacca), Anthony Daniels (C-3PO), Tim Rose (Amiral Ackbar), Warwick Davis (Wicket), Dave Prowse (Darth Vader) y Jeremy Bulloch (Boba Fett).

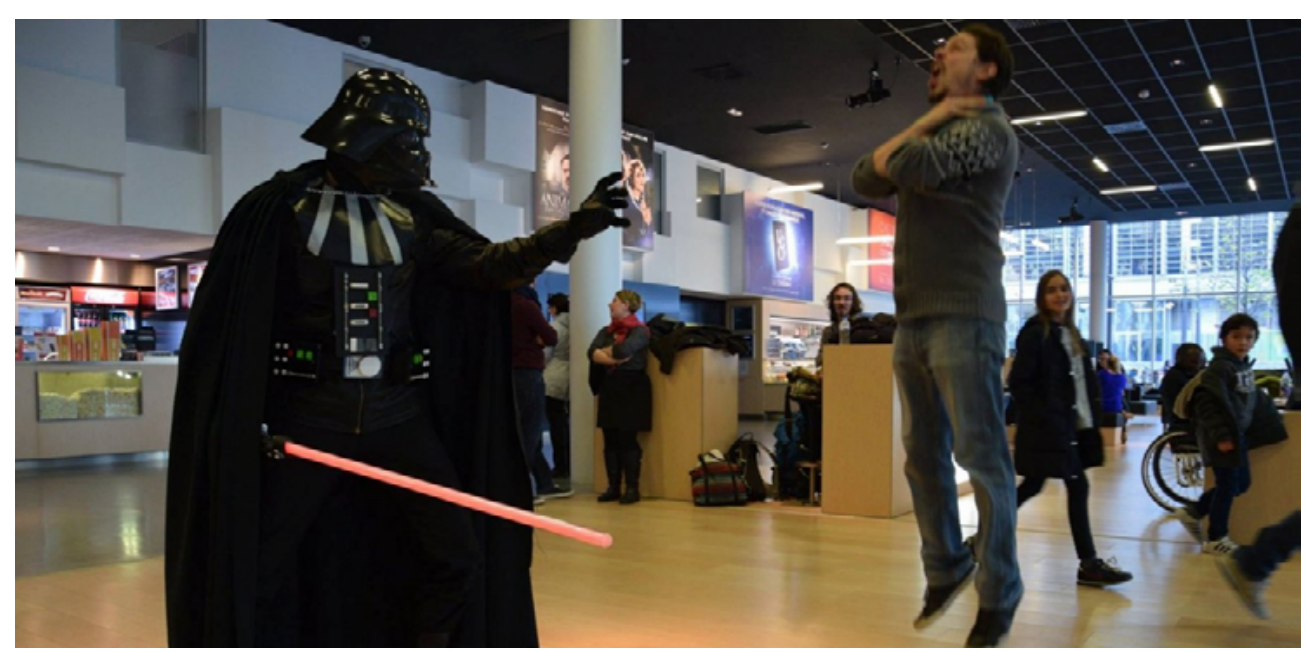

Figura 2. El Doctor Darkalain castigando a un estudiante rebelde en 2016, para la salida de Rogue One: A Star Wars Story (fuente: Hervé Labruyère). 
Parece difícil encontrar en este conjunto algún elemento que podríamos vincular con una crítica del orden económico dominante, inspirada, entre muchas otras corrientes, por la geografía radical (o crítica) que armaron en Estados Unidos pensadores como William Bunge, David Harvey y Mike Davis. Sin embargo, el mensaje político de las películas es claramente progresivo, ya que los y las rebeldes de la Alianza están luchando contra una dictadura abominable encarnada por el Emperador Palpatine (antes de ver a la Resistencia, liderada por Rey, Poe y Finn, derrotar al mismo Palpatine en el último capítulo de la saga Skywalker). ¿Será solo una coincidencia que el guerrillero interpretado por Forest Whitaker en Rogue One se llame Saw Gerrera? En su libro The Art of Rogue One: A Star Wars Story, Josh Cushing apunta que se escogió este nombre para recordar, por lo menos con los sonidos, a la figura del revolucionario más conocido de América latina (y tal vez de la galaxia), Che Guevara (figura 3):

Kiri Hart sugirió el uso de Gerrera, un personaje creado originalmente por George Lucas para la serie animada Star Wars: The Clone Wars. Ubicada dos décadas antes de los eventos de Rogue One, The Clone Wars vio a Gerrera (cuyo nombre es una referencia mnemotécnica al líder revolucionario Che Guevara) amargado por el conflicto galáctico que mató a su hermana. Rogue One seguiría ese hilo para descubrir como veinte años de opresión imperial acentuarían su resentimiento. (Kushins, 2016, 99)

4 ¡Mil gracias a Mario Alberto Escamilla por la referencia erudita! 

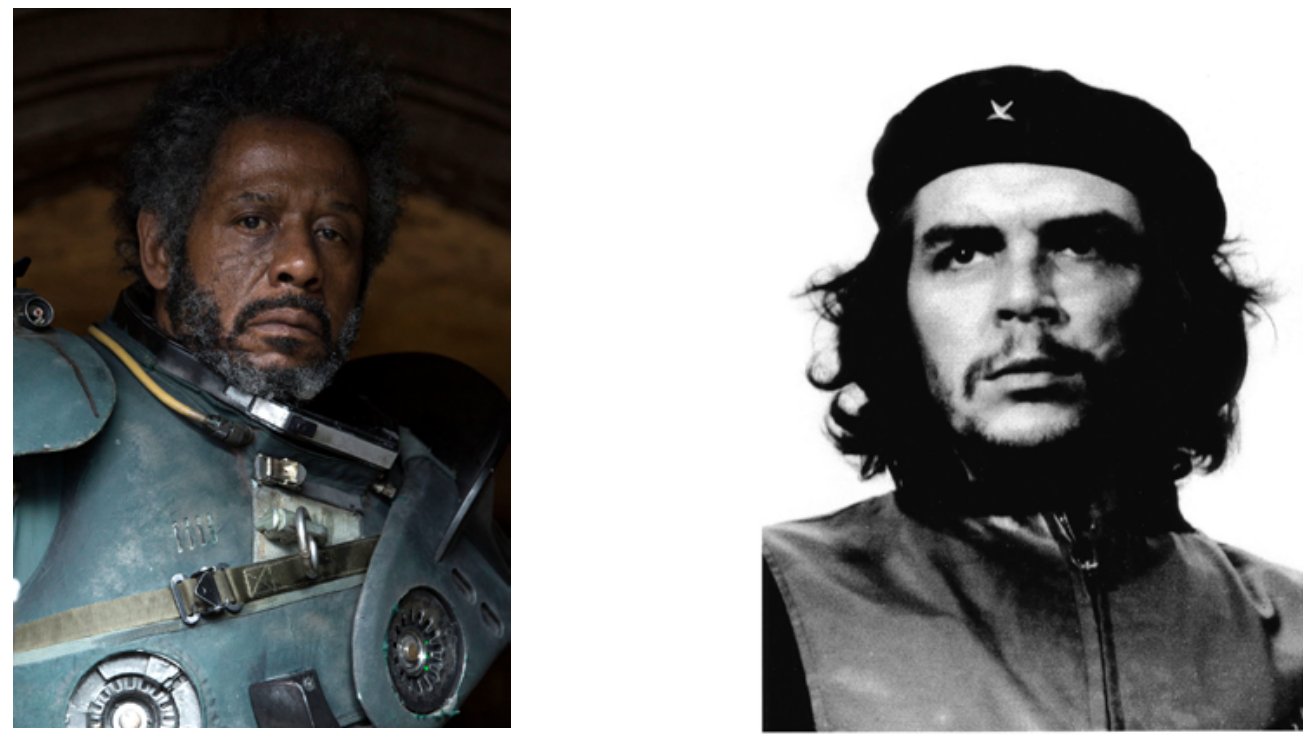

Figura 3. Saw Gerrera, el rebelde extremista de la película Rogue One (Star Wars Wiki. Wiki en français (2020, April 7). Articles Canon, Personnages masculins, Humain, Saw Gerrera. https://starwars.fandom.com/fr/wiki/Saw_Gerrera) y su modelo argentino (Witter, L. (2015, July 16). Che Guevara mort il y a 50 ans: comment sa photo a fini sur nos $t$-shirts. L'OBS. https://bit.ly/30HYWWW

Además, gran parte del universo de Star Wars está impregnado de dos temas que ocupan un lugar central en la mala conciencia de los Estados Unidos: el racismo y la esclavitud. De hecho, tanto en las películas como en las novelas, la denuncia del racismo humano hacia los y las no-humanas se acompaña de un recordatorio permanente de uno de los vicios iniciales de la sociedad norteamericana: la deportación y el trabajo forzado de tantos negros y negras africanas en las plantaciones de caña de azúcar y algodón de los antiguos Estados confederados. En Tatooine, Anakin Skywalker (un niño rubio con ojos azules) es un esclavo, hijo de una esclava, propiedad de un pequeño traficante de Mos Esley. Cuando la joven Padmé lo encuentra por primera vez en la tienda de Watto, en La amenaza fantasma (1999), le hace una pregunta terrible: “¿Eres un ... esclavo?”. La respuesta de Anakin es tan violenta como desesperada: "Soy una persona", para afirmar que su vida no se reduce a su estatus legal de bien mueble. Por otra parte, debemos recordar 
que (según las novelas del Universo expandido) Han Solo eligió romper con el Imperio porque este sistema político repugnante había esclavizado a muchas comunidades no-humanas y especialmente a los Wookies (entre los cuales, por su puesto, estaba su gran amigo Chewbacca).

Con todo, si bien podemos considerar que Star Wars refleja los valores de una izquierda estadounidense que hoy en día Donald Trump y sus acólitos suelen odiar y desdeñar (antiimperialismo, antirracismo, inclusión, solidaridad e igualdad de género), no encontraremos en las películas, dirigidas hacia a un público amplio, abierto a ideas generosas, pero finalmente bastante abstractas, un discurso condenando el sistema económico imperante en esta galaxia no muy lejana. Tal vez podríamos destacar una excepción en el Episodio VIII, The Last Jedi, cuando Finn y Rose visitan la extraordinaria ciudad casino de Canto Bight —Dubrovnik en nuestra realidad—. El lujo de los hoteles y palacios impresiona al stormtrooper que ha pasado a la Resistencia, pero su compañera le hace comprender que esta riqueza insolente no es sino el resultado de la explotación de miles de millones de trabajadores y trabajadoras oprimidas por compañías transgalácticas cuyo único propósito es engordar a sus accionistas.

Sin embargo, en las novelas o cómics Star Wars, el mensaje crítico puede llegar bastante lejos. Si queremos abordar las causas del mal profundo que ha plagado a la República y ha facilitado el surgimiento del Imperio, debemos poner en tela de juicio las desigualdades estructurales que impactan directamente a los y las explotadas, desheredadas y desposeídas de todos los planetas que sirven de telón de fondo para el choque milenario entre los Jedi y los Sith, entre el Bien y el Mal. Por ejemplo, en Medstar 1: Médicos de guerra, una novela de Michael Reaves y Steve Perry publicada en 2004, la heroína aclara la conexión entre el conflicto que ensangrienta la galaxia y los intereses económicos de los grupos que se benefician de dicho conflicto: "Era sobre todo un asunto de comercio y capitalismo, como la mayoría de las guerras, incluidas las guerras santas" (Reaves y Perry, 2005, 88). No estamos lejos de la fórmula atribuida a Jean Jaurès, el socialista francés asesinado en 1914 porque rechazaba la idea de una guerra contra Alemania: "El capitalismo 
lleva consigo la guerra como la nube lleva la tormenta". En realidad, se trata de la reformulación de su discurso del 7 de marzo de 1895 en la Cámara de los Comunes, anunciando con 19 años de anticipación los horrores de la Primera Guerra Mundial: "Siempre su sociedad violenta y caótica, incluso cuando quiere paz, incluso cuando está en estado de descanso aparente, lleva en ella la guerra, como una nube dormida lleva la tormenta" (Jaurès, 1959, 88).

Por lo tanto, no es completamente incongruente buscar en la literatura "starwarsiana" y, más particularmente en los trabajos más comprometidos publicados a partir de la década del 2000 —incluso en la literatura para jóvenes-, los fundamentos de un pensamiento crítico sobre nuestro capitalismo contemporáneo.

\section{EL PODER OCULTO DE LAS SOCIEDADES TRANSGALÁCTICAS}

El mundo de Star Wars está dominado por varios grupos industriales hegemónicos, compañías transgalácticas y consorcios financieros cuya codicia y cinismo no tienen nada que envidiar a nuestras propias compañías transnacionales. Este es el caso de los dueños de la Federación del Comercio que, en La amenaza fantasma, buscan imponer por la fuerza tratados injustos a todos los planetas abandonados a su suerte por senadores y senadoras corruptas hasta la médula. Codiciosos, cobardes, dispuestos a hacer cualquier cosa para aumentar su poder y riqueza, los neimodianos que asedian el planeta Naboo parecen directamente sacados de la junta directiva de Goldman Sachs, el imperio invisible que valía 700 mil millones de dólares a principios de los años 2010, o sea dos veces el presupuesto de Francia (Roche, 2011; Fritel y Roche, 2012), y cuyos líderes han encabezado la crisis de los subprimes, la bancarrota de Grecia y la especulación contra el euro (figura 4). 


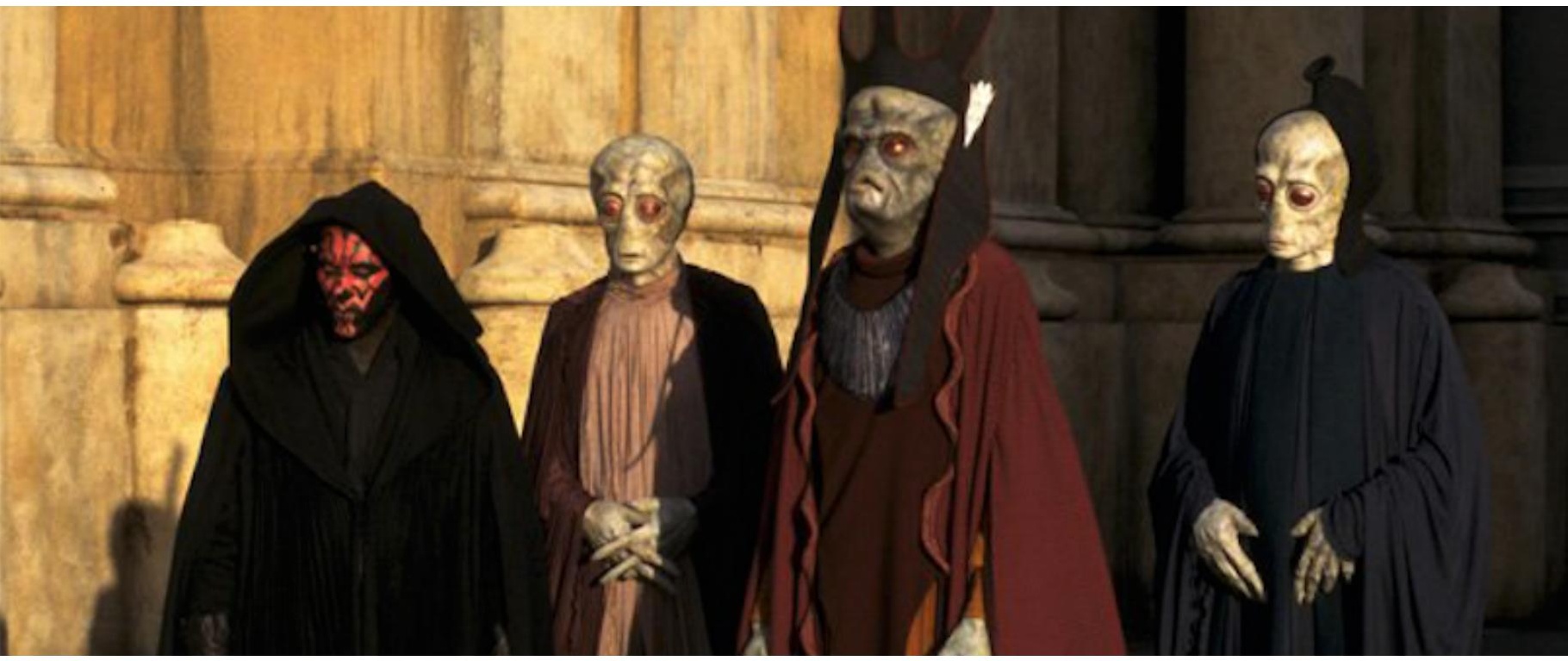

Figura 4. Bajo la influencia de los Sith, el virrey Nute Gunray aprovechó un proyecto de tributación de las rutas comerciales para intentar imponer el monopolio de su organización a la reina elegida de Naboo, la joven Amidala (Wookieepedia, The Star Wars Wiki. (2020, April7). Legends articles, Legislatures, Naboo Organizations, Trade Federation Ocupation Council. https://bit.ly/2D5NFYs).

Desafortunadamente para los y las habitantes de la galaxia, la Federación del Comercio no es la única en ocuparse de los asuntos de un mundo donde los conceptos de centro y periferia han mantenido todo su significado. Tal como lo destaca Drew Karpyshyn en Camino de destrucción, la República no es popular en los planetas del Borde exterior que son explotados por compañías cuyas oficinas centrales están ubicadas en el Núcleo y en particular en Coruscant, la capital intergaláctica. Razón por la cual el joven Dessel (el futuro Darth Bane) puede declarar a sus compañeros: “Todo está bien en el Núcleo: la gente goza de buena salud, es rica y feliz. La vida no es tan sencilla aquí en la Frontera" (Karpyshyn, 2008, 53). De hecho, los principales grupos industriales, financieros y comerciales de la galaxia han establecido en Coruscant al menos una "embajada" encargada de mantener buenas relaciones con los círculos del poder. A pesar del desarrollo de las tecnologías de la 
información y comunicación, sigue siendo esencial estar físicamente presente en la capital para afirmar su estatus político y social, gestionar sus negocios y cabildear.

Entre estas poderosas "transnacionales" se encuentra Incom Inc., líder en el mercado de naves espaciales por más de dos mil años. De la misma manera, los miembros del "Sector Corporativo", que controlan miles de planetas y aplican sin piedad las reglas del capitalismo más neoliberal, mantienen contactos cercanos y permanentes con Coruscant. Se trata de los representantes de las compañías más grandes de la galaxia que dieron origen a la Liga Corporativa Pan-Galáctica: Cybot Galactica, Kuat Shipyards, Merr-Sonn, Stellar Propulsion Rendili, Santhe / Sienar, Core Bank, Ayelixe / Krombine. Textiles, Millenium Entertainment, Chiewab Amalgamated Pharmaceuticals, etc. Sin olvidar a Tagge Company (TaggeCo), un conglomerado poderoso y diversificado con una gran cantidad de compañías en las industrias básicas (Bonadan Heavy Industries, Tagge Mining Company y GalResources), el sector manufacturero (computadoras Mobquet y Trast Gowix) y en el sector de los servicios.

Sin embargo, es solo a mediados de la década del 2000 que los autores y las autoras de la galaxia Star Wars se atrevieron a presentar de manera realmente crítica el capitalismo industrial y financiero intergaláctico, cada vez más presentado como un cáncer que está carcomiendo los fundamentos de la República y de la democracia. En el planeta Nox puesto en escena por Tim Lebbon en Amanecer de los Jedi, las "corporaciones" (término vago para designar cualquier tipo de compañía) manejan con un puño de hierro la estación Greenwood: "Ellas hacen la ley y la gente trabaja para ellas. La única seguridad aquí está diseñada para garantizar el funcionamiento correcto de la producción y proteger a los miembros de las corporaciones" (Lebbon, 2015, 211). El mismo término ha sido utilizado por Michael A. Stackpole en La guerra del Bacta (1997) para hablar de las compañías que producen el famoso bacta del planeta Thyferra. Esta droga milagrosa permitió a la Corporación Zaltin y a la Corporación Xucphra, que gozaban de una situación de monopolio, conseguir ganancias indecentes, especialmente durante el largo 
período de conflicto armado que comenzó con la llegada al poder del Canciller Palpatine, el futuro emperador. En 2000, en una novela juvenil titulada El día del juicio, Jude Watson reveló los trucos de una compañía minera transgaláctica bien conocida, llamada Offworld e instalada en Telos bajo el nombre de Unify para apropiarse de sus riquezas naturales. Para hacer olvidar a sus habitantes la problemática planteada por el saqueo del planeta, los líderes de Offworld lanzaron un vasto juego de azar llamada Katharsis (purificación) que daba a los participantes la esperanza de escapar algún día de su miseria. Como lo hace resaltar Den, un rebelde deseoso de acabar con esta gran empresa de lavado de cerebro, al participar voluntariamente a este juego los y las desposeídas hacen el juego de sus amos: “¡Miren a su alrededor, miren! ¿Tienen deudas? ¿Solo piensan en el dinero? ¡Perfecto, eso es lo que quieren! Y mientras calculamos nuestras posibilidades soñando con la fortuna, ellos destruyen nuestro mundo" (Watson, 2003a, 122).

En este sentido, Offworld no es muy diferente de Goldcorp, una compañía multinacional de extracción de oro que opera a través de diversas compañías establecidas en los países anfitriones. En Guatemala, su caballo de Troya es Montana Exploradora de Guatemala (Musset, 2014). Para disfrazar su rol activo en la destrucción del medio ambiente y el despojo de las comunidades indígenas, la corporación multiplica las campañas publicitarias destinadas a demostrar que desempeña un papel relevante en el desarrollo económico y social de las poblaciones marginales abandonadas anteriormente por el Estado; es lo que llamamos ahora "responsabilidad social de las empresas" — antiguamente era puro paternalismo-

Goldcorp es un productor líder de oro, enfocado en prácticas responsables, con una producción segura y de bajo costo en América. Posee un portfolio de activos que incluyen cuatro minas en Canadá, tres minas en México y cuatro más en Centro y Sudamérica; de larga duración y alta calidad que posicionan a la empresa a proveer valor a largo plazo ${ }^{5}$.

5 Argentina Mining. (2020, march 30). Expandiendo las Fronteras de la Oportunidad. https://bit.ly/3eVqOfi. 
En este campo, James Luceno es sin duda alguna uno de los escritores más críticos del equipo contratado por Lucasfilm, tal vez porque fue carpintero y guía turístico en América Central antes de convertirse en un escritor exitoso. En Star Wars: Darth Plagueis ataca a las compañías transgalácticas que socavan el poder de la República y juegan con el lado oscuro de la Fuerza. Este es el caso del Clan Bancario Intergaláctico (o Red Bancaria Intergaláctica según las fuentes) cuya influencia se extiende desde los Mundos del Núcleo hasta los planetas más distantes del Borde Exterior. Sus miembros hacen y rompen gobiernos, influyen en las elecciones, corrompen todo lo que tocan con el dinero que fluye por sus arcas. Según Luceno, Coruscant se ha convertido en una canasta de cangrejos donde los cabilderos de todo tipo pasan su tiempo seduciendo a los senadores útiles para llevar a cabo sus proyectos, tal como lo hacen descaradamente en Washington detrás de la escena del Congreso.

Es así como, al frente de Damask Holdings, Hego Damask — mejor conocido como Darth Plagueis- quiere apoderarse de los depósitos de plasma del planeta Naboo ofreciendo a cambio a sus líderes la oportunidad de participar plenamente en las actividades económicas y financieras de la galaxia, en una vasta área de libre comercio garantizada sin impuestos ni barreras aduaneras. En realidad, solo se trata de un saqueo. Como dice Palpatine, el aprendiz del Señor Sith: "Estas son puras tácticas desplegadas por la República para incitar a los mundos primitivos a renunciar a sus recursos" (Luceno, 2012, 160).

Una figura importante en las Guerras de los Clones, Pors Tonith es la ilustración de estos hombres de negocios corruptos y corruptores que se enriquecen a expensas de los más débiles: "Consideraba los negocios como una guerra. Durante generaciones, su familia gestionó por la fuerza la compra salvaje de empresas, e incluso de planetas enteros si fuera necesario" (Sherman y Cragg, 2006, 29). Afortunadamente, tales prácticas no pueden existir en nuestro mundo y el infame Pors Tonith no tiene nada que ver con Wilbur Ross, el multimillonario estadounidense especializado en la compra de compañías en dificultad revendidas con fuertes ganancias después de reestructuraciones y despidos en masas de sus empleados (figura 5). Apodado "el rey de la bancarrota", este honorable empresario ha sido elegido por Donald Trump 
para ocupar el cargo de Secretario del Comercio de los Estados Unidos.

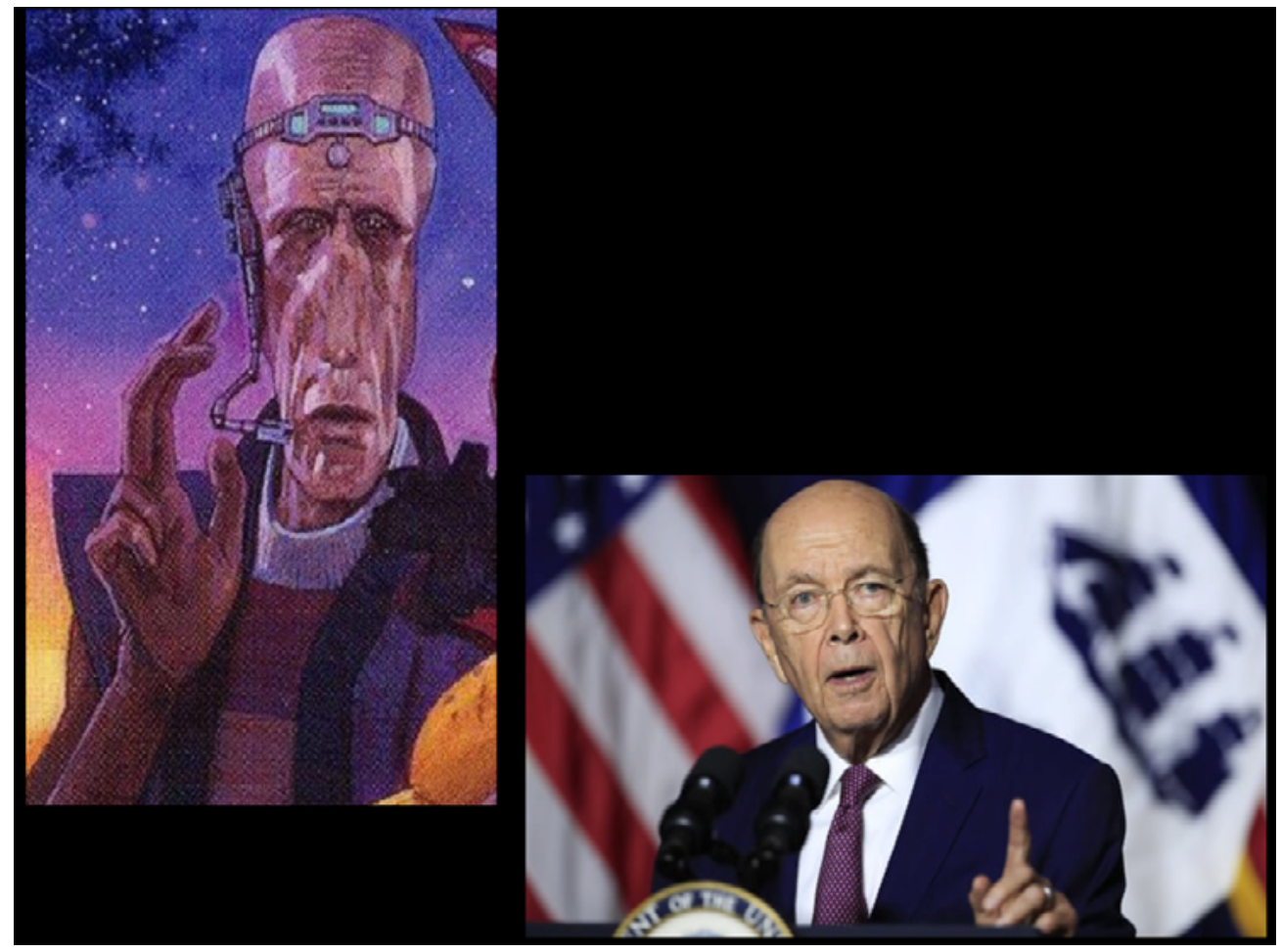

Figura 5. Pors Tonith (Star Wars Universe. (2020, March 30). Personnages. https:// bit.ly/39zOBQT) y Wilbur Ross (U.S. Embassy and Consulates in Brazil. (2019, July 26). U.S. Secretary of Commerce Wilbur Ross to Visit Brazil. https://bit. ly/2ZXDE8E), dos figuras del capitalismo globalizado.

Después de su disolución oficial, los herederos del Clan Bancario Intergaláctico mantuvieron su control sobre gran parte de la galaxia a partir de Muunilinst, su base original. En una misión secreta en este planeta dedicada a las finanzas, Leia recordaba a Luke y Han que su apodo era "La tierra del dinero" (Moneylend en la versión original) y que casi todas las personas ricas de la galaxia debían parte de su riqueza a los banqueros muuns que se habían infiltrado en todos los sectores de la economía (Wheeler, 2016, 112). Harnaidan, la capital de Muunilinst, presenta una arquitectura neoclásica que recuerda no solamente al sector financiero de Nueva York alrededor de Wall Street, sino también a un barrio bien conocido de la ciudad de Santiago. 


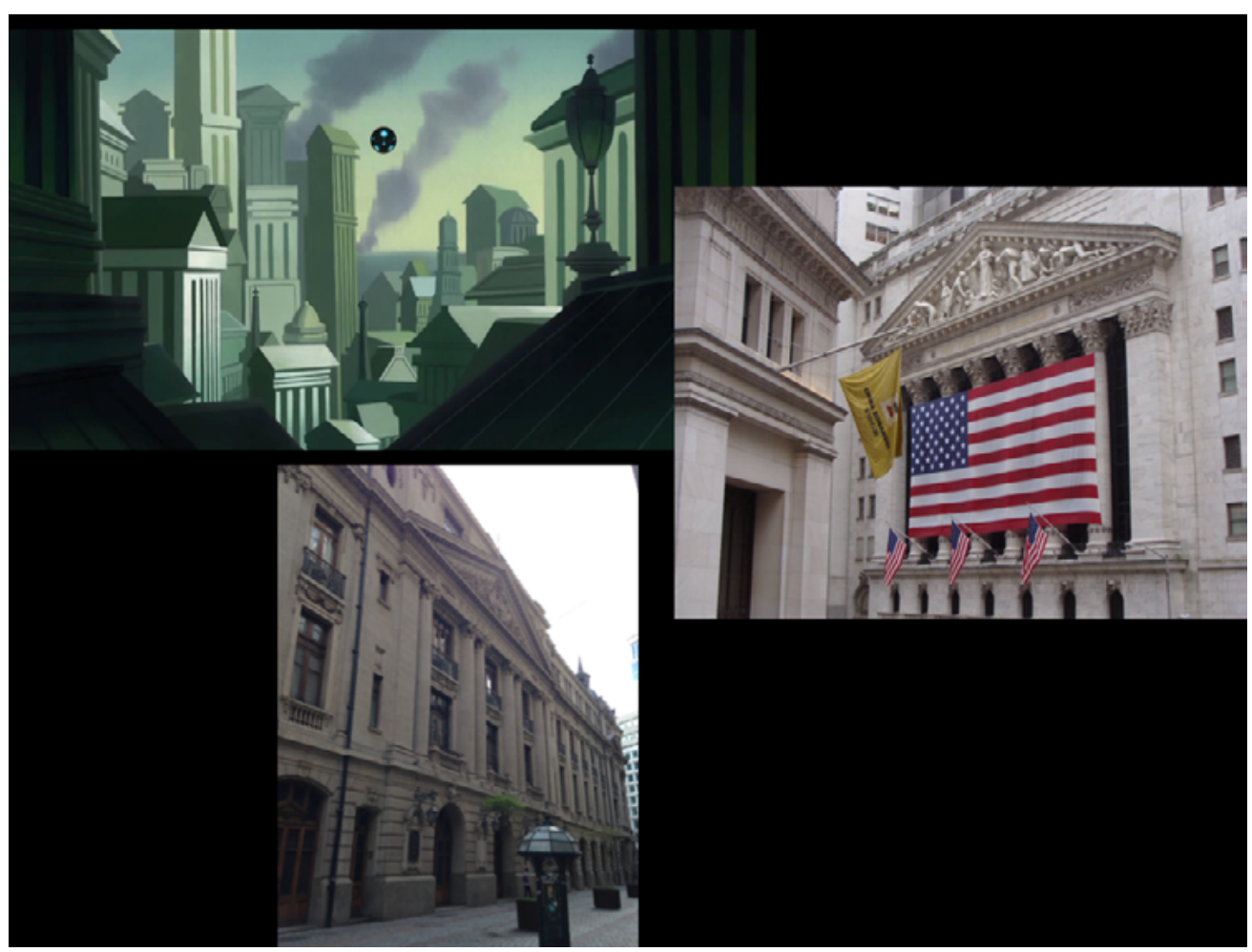

Figura 6. Harnaidan (Wookieepedia, The Star Wars Wiki. (2020, March 30). Legends articles, Capital Cities, Cities on Munnilinst. https://bit.ly/2OTeIc7), Wall Street y la Calle Nueva York de Santiago, Chile (fuente: Alain Musset).

En La última prueba de Troy Denning, un consorcio minero, el Technology Exploitation Group (TEG), desempeña nuevamente el papel del villano. Si bien el imperio se derrumbó, los héroes y las heroínas de la saga deben luchar ahora contra compañías sin fe ni ley que saquean y destruyen mundos enteros. Por supuesto, al igual que sus modelos reales, los verdaderos propietarios de esas grandes compañías están ocultos detrás de una nebulosa de empresas anidadas entre sí. Es así como el TEG pertenece al Galactic Syndicated, liderado por los hermanos Qreph, dos rodadores con prácticas dudosas. Cuando Lando Calrissian protesta contra la lógica de rentabilidad de la empresa cuya consecuencia directa será el despido de al menos un millón de mineros, Marvid responde cínicamente, como tantos otros expertos financieros ansiosos por aumentar las ganancias corporativas y los dividendos 
de sus accionistas: "la economía es una ciencia cruel" (Denning, 2015, 69). ${ }^{6}$ Solo cabe decir que, por supuesto, se trata también de una compañía off-shore: "Recuerde que la falla de Chiloon se encuentra fuera de cualquier jurisdicción galáctica. Caitheus y Marvid rompen muchas leyes. Su cuartel general debe instalarse en un lugar donde las autoridades no puedan alcanzarlos" (Denning, 2015, 19). En nuestra Tierra contemporánea, Galactic Syndicated podría haberse establecido en Panamá, Luxemburgo o las Islas Caimán.

\section{STAR WARS EN LUCHA CONTRA LOS MODOS DE DESTRUCCIÓN CAPITALISTAS}

En un sistema económico que se inspira en nuestra actual división internacional del trabajo, planetas-talleres alimentan los principales mercados consumidores de la galaxia, es decir, mundos enteros que no tienen la capacidad de mantenerse a sí mismos. Para los empresarios de Star Wars, como en cualquier otro sistema económico liberal, la mejor manera de reducir los costos parar incrementar los márgenes de ganancia es reubicar las unidades de producción en áreas gozando de ventajas comparativas indiscutibles: una fuerza de trabajo calificada y barata, una legislación muy flexible respecto a los derechos laborales y al medio ambiente, bajos impuestos, excelentes condiciones de transporte, etc. Tal como James Luceno lo apunta en Laberinto de Maldad para explicar la desaparición del sector industrial de Coruscant: "The Works han sido un área industrial dinámica hasta que los crecientes costos de producción llevaron a trasladar a otros mundos la producción de naves espaciales, robots y materiales de construcción" (Luceno, 2005, 174).

Consecuencia de esta estrategia económica, Bilbringi se convirtió en el mayor centro de producción de cazas y buques de guerra del Imperio gracias a las instalaciones industriales de vanguardia agrupadas en unidades de producción particularmente bien defendidas. El planeta Kuat también es parte de los "beneficiarios" de este proceso de globalización de los intercambios

6 Esta definición cínica recuerda las palabras de Tony Cleaver en su libro Economics. The Basics: "Economics is a seemingly cold and cruel science that, like it or not, treats labour just as any other resource" $(2011,49)$. 
que ha afectado a toda la galaxia. Durante la Antigua República, bajo el mando de las familias gobernantes, se convirtió en un centro gigantesco para la producción de vehículos interestelares (figura 7). Los Astilleros Kuat (CNK), con millones de trabajadores y trabajadoras operando en instalaciones industriales ubicadas en órbita alrededor del planeta, se especializaron en la fabricación de unidades muy grandes, particularmente para el sector militar (destructores estelares de clase imperial).

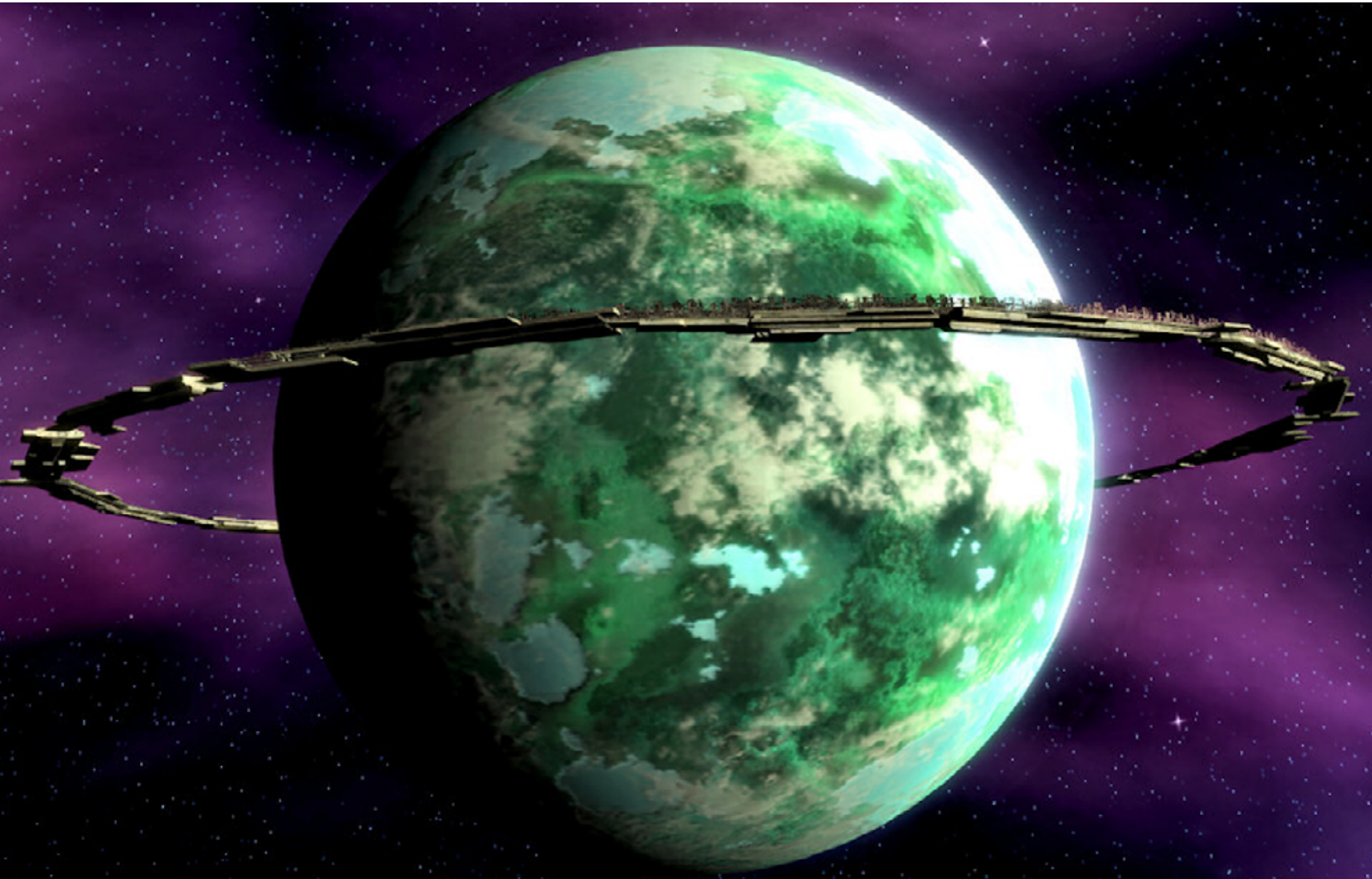

Figura 7. En órbita alrededor del planeta Kuat, los astilleros se han puesto al servicio del complejo militar-industrial favorecido por la política imperial (Game Guide (2020,March 30). SWOTOR - Kuat, la planète des chantiers navals. https:// bit.ly/39uOOFa). 
En Io, Jedi, Michael Stackpole nos dice que la CNK ha exportado sus técnicas de producción hacia otros mundos. Este es el caso de Xa Fel, un mundo del sector Kanchen que suministra el hiperimpulsor de naves ensambladas en la órbita de Kuat. La atmósfera está tan contaminada que los y las visitantes deben usar ropa protectora y una máscara de oxígeno para llegar allí. La República intentó imponer medidas de descontaminación a los gerentes de los astilleros, pero al no tener instrumentos eficientes para actuar, no tuvieron efecto. De manera general, con el fin de mitigar las molestias relacionadas con la producción manufacturera (ruido, congestión, contaminación, etc.), las actividades más sensibles han sido trasladas hacia planetas cuyos ecosistemas han sido destrozados por un desarrollo industrial devastador. Es así como el sistema de Fondor fue completamente trastornado por los talleres de construcción naval que se benefician de los minerales abundantes extraídos no solamente del subsuelo, sino también de sus lunas y asteroides: "Mientras que las grandes compañías que controlaban Bilbringi, Kuat, Sluis Van y otros centros de construcción naval hicieron un esfuerzo mínimo para preservar el medio ambiente, nada se hizo de esta manera en Fondor" (Luceno, 2001, 268).

De la misma manera, en la novela Renacimiento de Greg Keyes, parte del ciclo de la Nueva Orden Jedi, las y los pilotos de la Nueva República se reúnen en el planeta Eriadu donde aguantan con mucha dificultad una atmósfera aturdida por hidrocarburos, azufre, ozono y amoníaco. Los paisajes urbanos están marcados por enormes rascacielos industriales que se desprenden de un cielo amarillo pálido, oscurecido por los humos de las fábricas. Corran Horn, líder del grupo responsable de combatir al invasor Yuuzhan Vong, da a sus compañeros y compañeras la explicación de este desastre ecológico: "Aquí se maquilan los productos al menor costo sin tener en cuenta el medio ambiente. El olor es un subproducto de la industria" (Keyes, 2002, 101). Antiguo planeta industrial especializado en la fabricación de robots, Mechis III sufrió la misma suerte. Su superficie está cubierta casi en su totalidad por fábricas, líneas de montaje y unidades administrativas. En los intersticios de este mundo inhumano, se extienden las zonas habitadas y los vertederos donde 
se acumulan los desechos de los procesos productivos (Anderson y Moesta, 1999, 112).

Sin embargo, es en el planeta Duro que una industrialización sin control, en busca de un beneficio inmediato, tuvo las consecuencias más dramáticas: este mundo antes verde ha sido convertido en un vasto desierto del cual sus habitantes huyeron para refugiarse en ciudades orbitales. Las lluvias que caen sobre un suelo que se ha vuelto estéril están cargadas de polvo tóxico, herencia de los días en que las chimeneas de las fábricas arrojaban continuamente nubes de humo negro. Al igual que en las antiguas ciudades manufactureras de América del Norte, en Chattanooga, por ejemplo, se intentó desarrollar un programa de rehabilitación para volver a la vida la tierra contaminada por efluentes químicos y metales pesados. Se realizaron experimentos para limpiar pantanos, purificar el suelo y hacer que el aire fuera respirable, pero los resultados han sido limitados por la falta de recursos técnicos y financieros: "Lograron desarrollar seis ecosistemas en miniatura y sanear una gran área de pantanos, produciendo un suelo purificado ideal para la reconstrucción. Finalmente, lograron crear la primera superficie cultivable del planeta, desde la salida de los durosianos" (Tyers, 2001, 43).

Con todo, la situación de Duro no es imaginaria: las descripciones apocalípticas de estas tierras que ya no son aptas para la vida humana solo reflejan la angustia de nuestras sociedades frente al daño ecológico causado por la industrialización, la búsqueda de ganancias inmediatas y el capitalismo globalizado. Al impulsar actividades contaminantes en los países del Tercer Mundo, en Asia o en los países-talleres de América Latina, las grandes corporaciones transnacionales solo trasladan el problema sin resolverlo. El leitmotiv del "desarrollo sostenible", ampliamente explotado por la clase política para pretender cumplir con las expectativas de la sociedad civil (al principio en las naciones del Norte, pero ahora también en las del Sur global), a menudo resulta solo en medidas del tipo "durosiano": un cosmético básico aplicado a heridas incurables.

Por eso la princesa Leia, enviada a Duro para orquestar la regeneración del planeta, fue transformada por Kathy Tyers, autora de Punto de equilibrio, 
en la portavoz de los grupos de presión ambiental siempre muy activos en los Estados Unidos. En este planeta muerto, debe luchar constantemente contra una administración central que se niega a darle los medios necesarios para implementar su programa: "Estaba cansada de esta nueva generación de burócratas que ahora proliferaban en Coruscant" (Tyers, 2001, 42). No cabe duda de que, frente a los senadores y las senadoras miedosas o corruptas de Coruscant, Greta Thunberg hubiera lanzado un grito de alarma muy parecido al que lanzó en la Organización de Naciones Unidas el 23 de septiembre de 2019:

¿¿Cómo se atreven?! Han robado mis sueños y mi infancia con sus palabras huecas. $Y$, sin embargo, soy una de los afortunados. La gente está sufriendo. La gente se está muriendo. Ecosistemas enteros se están derrumbando. Estamos en la antesala de una extinción masiva. Y ustedes de lo único que pueden hablar es de dinero y cuentos de hadas de un eterno crecimiento económico. ${ }^{7}$

Ahora bien, en muchos aspectos, la situación en Fondor o Duro recuerda la zona fronteriza entre México y los Estados Unidos, donde han florecido gigantescas naves industriales conocidas como maquiladoras. El sistema se estableció en 1965 cuando el gobierno de Washington finalizó el programa "Braceros" que permitía a los campesinos mexicanos obrar como trabajadores temporales en las grandes granjas de California y luego en el sector industrial. La creación de estas unidades de producción permitió a los empresarios del norte utilizar una mano de obra abundante que no estaba sujeta a las reglas sociales vigentes en su propio país. Para los Estados Unidos, la medida también tenía como objetivo mantener al sur de la frontera una parte importante de los candidatos y las candidatas a la inmigración que cruzaban la frontera ilegalmente. A juicio de los líderes mexicanos, esta actividad ayudó a fomentar el desarrollo de una región periférica y marginada, fuertemente afectada por las medidas restrictivas impuestas por su gran vecino. Este proceso culminó con la construcción de plantas gemelas ubicadas a ambos lados de la

7 Arlyn, J. (2019, September 24). Se han robado mi infancia: Con 16 años Greta Thurnberg da un contundente discurso a lideres en la ONU. Entrepreneur. https://bit.ly/2WSMh27 
frontera internacional. Al norte, un establecimiento reunía las funciones de mando y gestión (este es el papel asignado a Coruscant), al sur (el equivalente geopolítico y económico de Fondor), la planta de ensamblaje solo se encargaba de actividades productivas basadas en el trabajo manual, aprovechando una legislación menos estricta que en los Estados Unidos (figura 8).

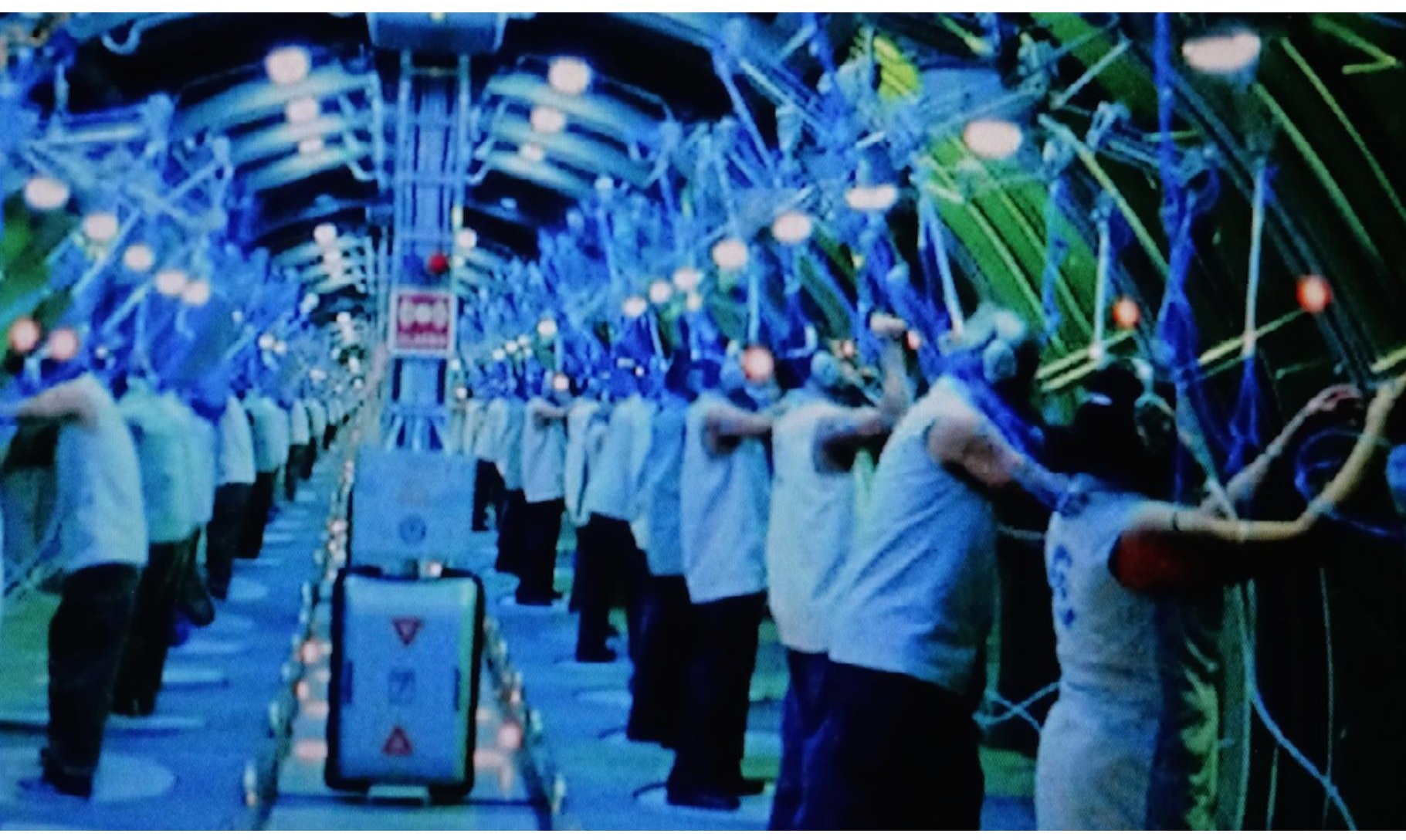

Figura 8. Las maquiladoras de Tijuana en la película de ciencia-ficción del mexicano Alex Rivera, Sleep Dealer (Rivera A. (Director). (2008). Sleep Dealer [film]. Likely Story and This is That Productions). Los empleados están conectados con robots que hacen el trabajo del otro lado de la frontera. Como lo dice el dueño de la empresa a los recién llegados: "Damos a los EE-UU todo lo que han querido siempre: la fuerza laboral sin los trabajadores".

En el campo de las políticas ambientales, la situación de Duro también se inspira directamente en la zona fronteriza entre México y los Estados Unidos. 
En 1983, ambos países firmaron un acuerdo de cooperación para la protección y mejora del medio ambiente (Convención de La Paz), que fue reforzado en 1992 por un nuevo Plan Ambiental Integral Fronterizo. El propósito de estos acuerdos era reducir los niveles de contaminación y desarrollar programas de investigación sobre los ecosistemas de la región transfronteriza. Sin embargo, como en el caso de Duro, estos diferentes tratados solo han conseguido efectos limitados. A pesar de todas las declaraciones de intenciones, el medio ambiente sigue amenazado por el aumento de las actividades industriales y el crecimiento de la población urbana en una región caracterizada por su clima semidesértico. Por lo tanto, es fácil entender por qué el problema ambiental aparece tan importante en una "galaxia lejana" que nos es sino el reflejo de nuestra realidad: para los y las habitantes de Austin (Texas) o Phoenix (Arizona), los planetas de Fondor y Duro no se encuentran a años luz de su hogar. Están a la mano y se llaman Matamoros (Tamaulipas), Nogales (Sonora) o Ciudad Juárez (Chihuahua).

\section{EXPLOTACIÓN Y DESPOSESIÓN: LOS DOS PILARES DEL CAPITALISMO TRANSGALÁCTICO}

Durante décadas, nuestras representaciones del mundo industrial han sido directamente relacionadas con la noción de progreso, descartando sin vergüenza la problemática ecológica. El dióxido de carbono emanado hacia la atmósfera aparecía con frecuencia como un equivalente de los índices bursátiles: más dióxido de carbono en el aire correspondía a un mejor puesto en la jerarquía del mundo desarrollado, tal como lo ha demostrado Enrique Aliste en sus estudios sobre Concepción de Chile y las políticas desarrollistas del gobierno chileno a mediados del siglo XX.

No obstante, en la década de 1990 y principios de 2000, la noción de saqueo ecológico fue una de temáticas más utilizadas por los y las escritoras de la galaxia de Star Wars con el propósito de poner en tela de juicio los modos de producción (o destrucción) capitalista. En 2015, en su novela $L a$ huida del contrabandista, Greg Rucka no dudó en utilizar términos que ya 
tenían sentido para un público de jóvenes adolescentes por fin conscientes de los peligros y amenazas conllevadas por un desarrollo insostenible. Cyrkon, un mundo que alguna vez fue idílico, ha sido víctima de un sistema productivo que amenaza también el futuro de nuestro planeta (figura 9):

Desde entonces, su atmósfera se había vuelto fatal. Industrias y negocios habían cargado el aire con toxinas. Las temperaturas se habían disparado, la superficie había comenzado a calentarse y el resultado fue un efecto invernadero irresistible cuya consecuencia inmediata es que hoy en día solo se puede vivir debajo de una cúpula, so pena de muerte. (Rucka, 2015, 52).

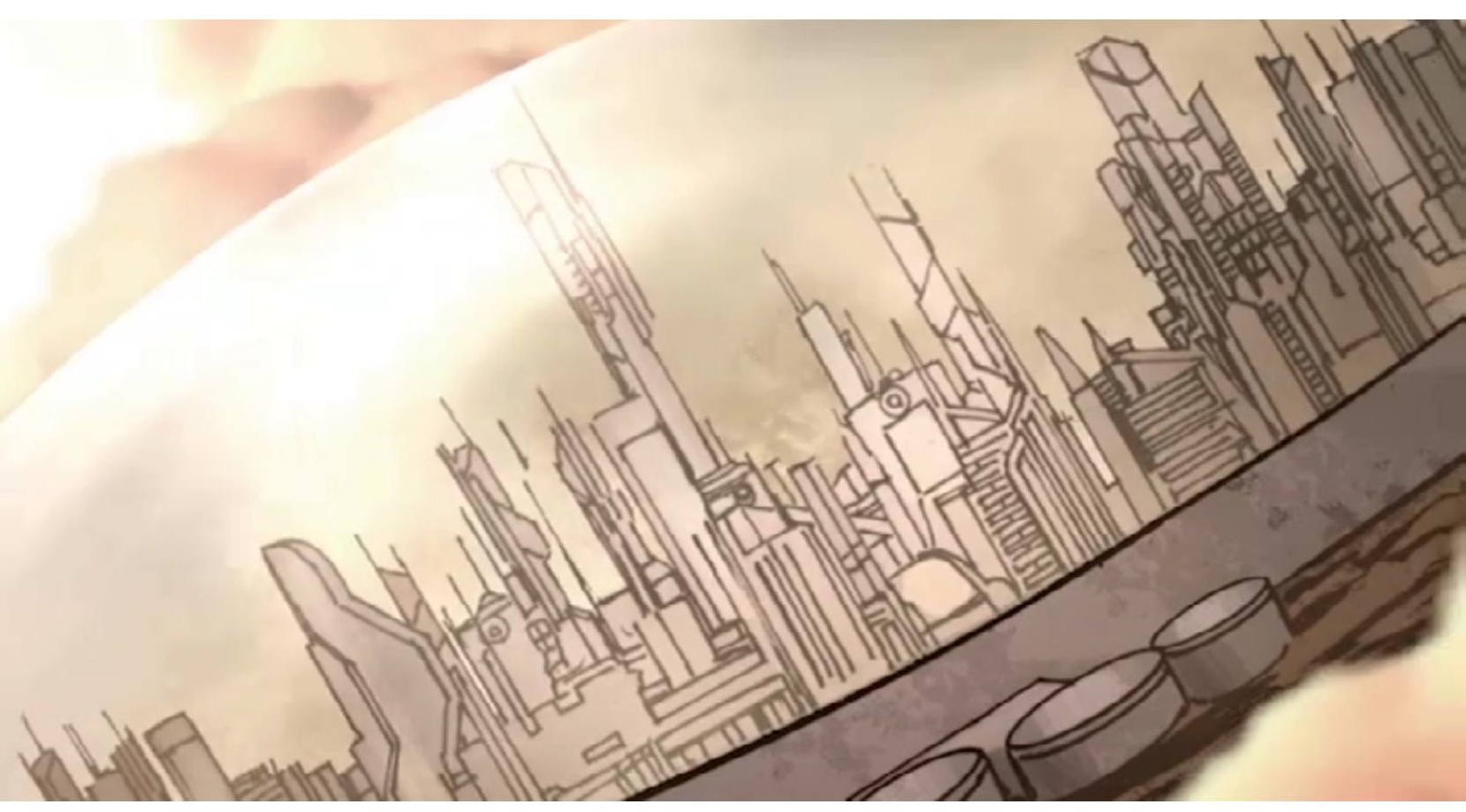

Figura 9. La capital de Cyrkon, Motok, está protegida por una cúpula que la aísla de una atmósfera tan contaminada que el aire se ha vuelto inhalable (Wookieepedia, The Star Wars Wiki. (2020, March 30). Canon articles, General location stubs, Capital cities, Cyrkon locations. https://bit.ly/3g1FZ88).

Sin embargo, con el tiempo, la perspectiva crítica se ha ampliado y 
profundizado, tal vez porque la crisis de 2008 puso de manifiesto la injusticia de un sistema económico basado en una carrera frenética para las ganancias y en el desprecio de los seres humanos. Sin entrar en un análisis marxista de las relaciones de producción y dominación, los cómics y las novelas de la saga Star Wars se han interesado cada vez más en las clases sociales inferiores cuya fuerza laboral es explotada por líderes sin vergüenza. Así, según Jude Watson, la compañía Offworld es: "una sociedad sin escrúpulos que esclavizó a miles de personas de todos los orígenes para explotar sus vastos complejos mineros" (Watson, 2002a, 88). En Dinastía de la maldad, Drew Karpyshyn no duda en usar los mismos términos para describir a la "Compañía Minera del borde exterior" que explota las minas de cortosis en Apatros: "una empresa famosa por tratar a sus empleados contratados como esclavos" (Karpyshyn, 2011, 119).

La temática de la esclavitud capitalista es el telón de fondo de la novela de Claudia Gray, Maestro y aprendiz, que se desarrolla cuarenta años antes de Una nueva esperanza. Qui-Gon Jinn y Obi-Wan Kenobi deben enfrentar una compañía transgaláctica omnipotente - la Czerca - que quiere apoderarse de los recursos del planeta Pijal y cuyos empleados no son sino meros esclavos condenados al trabajo perpetuo para reembolsar sus deudas o porque cometieron delitos menores. Lograron su meta sin dificultad porque las autoridades del planeta, seducidas por las sirenas del neoliberalismo, escogieron el camino de la privatización integral de todas las actividades tanto industriales como de servicios, entre las cuales el sistema penal: "Hace una generación, el sistema Pijal no contemplaba largas penas de cárcel. Ahora, son obligatorias para un sin fin de delitos, incluyendo los más pequeños. Por lo tanto, hay más comportamientos criminales castigados por una servidumbre penal perpetua" (Gray, 2019, 263).

Ahora bien, la empresa privada no es la única responsable de este proceso. De hecho, sin volver a las preguntas esenciales formuladas por Mehrdad Vahabi sobre el estado depredador y su papel en el despojo de los más vulnerables en nombre del "bien público" (una noción que sirve a menudo para justificar la santa alianza establecida entre lo político y lo financiero), no 
debemos olvidar que, en la galaxia Star Wars, las compañías transgalácticas operan en perfecta simbiosis con las estructuras del Imperio. Incluso en los tiempos más remotos del calendario starwarsiano, la cuestión social se ha convertido en una temática central. Este es el caso en Amanecer de los Jedi de Tim Lebbon, ubicado en el año 25.793 antes del año cero de la saga que corresponde a la Batalla de Yavin (Episodio IV, Una nueva esperanza). En esta novela sobre el comienzo de la lucha milenaria entre los Sith y los Jedi, aprendemos que la explotación de los trabajadores de Nox es una regla clara:

Las personas nacían y morían en Nox, y sus vidas, del principio al final, eran completamente planeadas. La mayoría de ellas ganaba lo suficiente para sobrevivir en una de las cúpulas, a veces dándose algunas fantasías. Pero abandonar el planeta requería mucho más de lo que la mayoría de la gente podía ahorrar durante toda su vida. Y sin duda alguna, las empresas no querían que el sistema cambiara (Lebbon, 2015, 226).

Drew Karpyshyn va aún más lejos en su novela Camino de destrucción, al explicar cómo las injusticias sufridas por el joven Dessel en las minas de Apatros lo llevaron a seguir el camino de los Sith. Si bien el minero explotado llega a abrazar el "Lado Oscuro de la Fuerza" convirtiéndose en el temible Darth Bane, su revuelta contra empresarios codiciosos y capataces brutales tiene sentido y le otorga un capital de simpatía compartido por lectores y lectoras más acostumbradas a seguir las aventuras de los nobles caballeros Jedi. De hecho, la famosa Empresa Minera del Borde Exterior suele explotar sin piedad a sus empleados que trabajan en condiciones pésimas y por un salario ridículo. Particularmente robusto, Dessel comenzó a trabajar a los trece años $\mathrm{y}$, al igual que todos los demás mineros, estaba pagado de acuerdo con la cantidad de mineral que podía extraer cada día del suelo al riesgo de su vida.

En su análisis de la situación de la clase trabajadora en Apatros, Karpyshyn no descuida ningún aspecto de la sociología y la economía local. De este modo, la compañía tiene sus propias tiendas cuyas tarifas son prohibitivas, pero que ofrecen facilidades de crédito para mantener a los mineros y sus familias en una cadena perpetua: 
El mercado ofrecía productos básicos a precios exorbitantes. La tienda estaba feliz de dar crédito, la compañía proponiendo tasas de interés obviamente escandalosas; así se aseguraba de que los clientes trabajaran aún más en las minas para pagar sus compras (Karpyshyn, 2011, 32).

En el cómic Chewbacca: Las minas de Andelm, el infame Jaum utiliza la misma técnica que la Empresa Minera del Borde Exterior de Apatros (una deuda contraída con el empleador) para obligar a Arrax y a su hija a trabajar en el infierno de las cuevas de escarabajos.

En Apatros, la compañía minera descuenta de los salarios no solamente el costo del transporte de los empleados entre su hogar y su lugar de trabajo, sino también un alquiler excesivo para viviendas insalubres. Para protegerse en el caso de un accidente, los mineros pueden contratar un seguro, pero su precio y la ausencia de garantías reales hacen que hasta los empleados más productivos lo descarten. Al final, tal como subraya el autor:

Pocos mineros alcanzaban la edad bendecida de la jubilación. Los túneles les quitaban la vida a muchos de ellos, aplastados por deslizamientos de tierra o quemados vivos cuando chocaban con una bolsa de gas explosivo en la roca [...] Los hombres de sesenta años parecían noventa (Karpyshyn, 2008, 27).

Si solo se tratara de una cuestión de eficiencia y rentabilidad destinada a llenar lo más pronto posible los bolsillos de los accionistas de la compañía minera, estas condiciones de vida en sí mismas serían escandalosas. Pero Karpyshyn también lo ve como una estrategia deliberada de la compañía para debilitar, subyugar y dominar a sus trabajadores. Su propósito es asegurarse de que, mediante el trabajo excesivo y las privaciones, los mineros terminen aceptando su destino, sin tener la fuerza de rebelarse.

¿Cómo no ver en estas descripciones de un planeta imaginario el reflejo de situaciones ampliamente difundidas en nuestra Tierra? El autor de Camino de destrucción parece haber tomado como modelo los estudios de Federico Engels sobre la Situación de la clase obrera en Inglaterra, por ejemplo, cuando habla del destino de las desafortunadas mujeres y sus niños que dependen únicamente de las capacidades físicas del jefe de familia para sobrevivir: 
[...] cuando el hombre, de cuyo trabajo vive esencialmente la familia y cuya actividad penosa exige más alimentación - y que por consecuencia es el primero en sucumbir-, cuando ese hombre cae enteramente enfermo, sólo entonces comienza la gran miseria, es entonces que se manifiesta, de modo verdaderamente estallante, la brutalidad con la cual la sociedad abandona a sus miembros, precisamente en el momento en que tienen más necesidad de su ayuda". (Engels, 1845, 132)

El mismo Karpyshyn no duda en hacer de las desigualdades sociales la principal causa de los conflictos que trastornan la República y amenazan con romperla. En Dinastía de la maldad, así se evoca la situación de Doan, cuya insolente prosperidad se basa en la explotación de minerales raros que se exportan hacia los centros industriales más importantes de la galaxia:

Pero esta riqueza seguía siendo el privilegio de la nobleza que llevaba una vida de opulencia en propiedades muy privadas y dominaba el resto del planeta. La gran mayoría de la población estaba conformada por castas inferiores, individuos condenados a pasar sus vidas en tareas físicas extenuantes o en trabajos de baja categoría sin posibilidad de cambio (Karpyshyn, 2011, 34).

Lejos de los palacios donde los miembros de la oligarquía local se la pasan muy bien, los parias de la tierra viven en tugurios y, a veces, en cuevas oscuras. Al igual que los trabajadores de París retratados por Émile Zola en $L a$ taberna (L'Assommoir, 1877) se encuentran por la noche en cantinas sórdidas para tragar bebidas alcohólicas y olvidarse de sus vidas miserables.

A la explotación pura y simple no solamente de los mineros, sino también de todos los y las trabajadoras del conjunto de la galaxia, se agrega el despojo sistemático de las comunidades indígenas cuyos recursos "naturales" son apropiados por compañías depredadoras, a menudo con el apoyo de las autoridades políticas locales. Es el caso por ejemplo de Bandomeer, mundo retratado por Jude Watson en su novela The Dark Rival: "Este mundo estaba condenado a la desolación. La mayoría de las minas estaban controladas por las grandes compañías que se llevaban la riqueza acumulada. Nada volvía a los nativos" (Watson, 2002b, 9). 


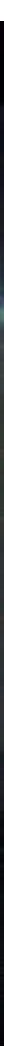

Figura 10. En Bandomeer la minas han arruinado gran parte del ecosistema del planeta (Reedar A. (2020, March 30). Bandomeer. Star Wars Role Play Amino. https://bit.ly/3g3QZ1l).

El planeta Lothal (lugar central de la serie de dibujos animados Star Wars Rebels) conoció la misma suerte con la confiscación por el imperio de las minas de doonium, metal ultra-resistente utilizado para fabricar los cascos de los destructores estelares. En su novela Star Wars: Thrawn, Timothy Zahn nos explica por qué y cómo este proceso de desposesión sistemática empujó a los y las habitantes a rebelarse:

Entre otras consecuencias cabe destacar la expropiación de los campesinos, a veces para construir un nuevo complejo militar o una nueva nave industrial, pero en la mayoría de los casos para expandir una instalación minera. Por supuesto, los campesinos se quejaban de esas reubicaciones forzadas (Zahn, 2018, 425). 
En Telos, la empresa Unify ha explotado sin remordimientos las tierras sagradas de los Telosianos, despreciando abiertamente su cultura y sus tradiciones. Para tratar de acabar con este despojo, se formó un partido ecologista, pero el gobierno lo prohibió:

Fuimos los primeros en protestar cuando las autoridades entregaron nuestros lugares más sagrados al cuidado de Unify. Les preguntamos porqué nuestras tierras se pusieron bajo el control de intereses privados, porqué tuviéramos que confiar en la palabra de una corporación que afirma salvaguardar y proteger estas mismas tierras. (Watson, 2003a, 49).

En The Evil Experiment, otra novela para adolescentes, la misma Jude Watson expone también el caso del planeta Sorrus, cuyos habitantes fueron desposeídos de sus tierras por empresas dedicadas a una agricultura intensiva que devasta el medio ambiente. Las grandes infraestructuras construidas con apoyo estatal solo benefician a los sectores "modernos" de la economía, en detrimento de las comunidades tradicionales empujadas hacia los márgenes del desierto. El jefe de la tribu víctima de esta forma clásica de extractivismo declara amargamente:

Teníamos plantaciones y no nos faltaba nada. Es cierto que nuestra vida era dura, pero nos convenía. Luego, hace diez años, se construyó una presa. El agua fue desviada de nuestras tierras. Luego vinieron inviernos particularmente duros, un año tras otro. Los pocos campos cultivables se volvieron áridos. (Watson, 2003b, 62).

"Nihil novi sub sole" ("nada nuevo bajo el sol"), como lo decían los antiguos romanos. En el sur de Chile el pueblo mapuche experimentó los mismos estragos cuando tuvo que enfrentar el poder de compañías transnacionales que querían implementar grandes proyectos hidráulicos en sus tierras con el acuerdo del gobierno (en nombre del progreso, del desarrollo y la modernidad) hasta el punto de que sus hijos e hijas fueran presentadas como "terroristas" por las autoridades. En una entrevista de 2014 para la revista Divergences2, Isabel Turuy Patzan, alcalde de la aldea del Pilar II en San Juan Sacatepéquez (Guatemala), se quejaba de los mismos crímenes cometidos contra su comunidad por la empresa CEMPRO: 
A raíz de esto pues, se dio una deforestación de bosques nativos, de la fauna y todo. Una extensión de 84,5 hectáreas de bosques fue deforestada, que es una lástima. Y también la destrucción de nuestros cerros sagrados, una privatización de nuestro cerro sagrado, que, para nosotros, para nuestra cosmovisión maya, significa mucho. Es ahí donde nosotros realizamos ofrendas a nuestros antepasados, lo que se cosechaba en la tierra, pero lastimosamente llegó el impacto de la empresa, que privatizó y hasta ahora ya no tenemos libre acceso a los lugares sagrados en el área. (Musset, 2014, transcripción propia)

De allí que, en las novelas y los cómics de Star Wars que se atreven a echar una mirada crítica a las realidades económicas de una galaxia que no nos parece tan lejana, estamos justamente muy lejos de las declaraciones relajantes del capitalismo "social" o del capitalismo "creativo" mimado por Bill Gates y los defensores ingenuos (o serviles) de un capitalismo con cara humana (Kinsley, 2008; Cocco y Szaniecki, 2015).

\section{CONCLUSIÓN: ¡PROLETARIOS DE TODA LA GALAXIA, UNÍOS!}

Cuando las condiciones de explotación se vuelven insoportables (o cuando la conciencia de la inequidad de dichas condiciones llega a despertarse), solo se abre un camino para los oprimidos/oprimidas y desposeídos/desposeídas de la galaxia: la revuelta. Es lo que ocurre en la película Solo, A Star Wars Story, cuando los y las esclavas de las minas de Kessel logran liberarse de sus amos gracias a la ayuda de la droida L3-37 que lucha y muere gritando: “¡Revuelta! ¡Revuelta! ¡Muera la opresión!”. En Doan, otro planeta minero descrito por Drew Karpyshyn en Dinastía de la maldad, un movimiento de resistencia exigiendo la igualdad política y social logra organizar a los y las trabajadoras explotadas por la casta de los nobles. Si bien la represión ha sido terrible, la determinación de los principales líderes nunca afloja. Es el caso de Draado, contaminado por el Lado Oscuro, pero cuyos discursos fascinan a los y las oprimidas que no tienen nada que perder: "Los nobles no nos respetaran hasta que aprendan a temernos, dijo, mirando a los demás. Debemos hacerles temer por sus vidas. Debemos llenar sus corazones con terror" (Karpyshyn, 
2011, 115). Hay un poco de Robespierre, el famoso revolucionario francés decapitado en 1794, en este minero originario de un planeta perdido del Borde Exterior. El mismo Robespierre que, en su discurso del 17 Pluviôse del Año II de la República, proclamaba: "La fuerza del gobierno popular en la revolución es a la vez virtud y terror: virtud, sin la cual el terror es fatal; terror, sin el cual la virtud es impotente" (Robespierre, 2012).

Sin embargo, en la galaxia Star Wars, las revueltas populares contra las clases dominantes son generalmente ahogadas en la sangre y parecen hacerse eco de la cuarta estrofa de la primera versión de la Internacional: "El engranaje nos va a torcer: / El capital es triunfante; / La ametralladora hace orden / Despedazando a la mujer y al niño”. En Apsolon, por ejemplo, los y las trabajadoras organizaron importantes campañas de sabotaje en fábricas y centros de producción para luchar contra sus propietarios. A pesar de represalias crueles consiguieron mejores condiciones de vida e incluso el derecho a votar. Lamentablemente esta "revolución pacífica", para usar las palabras de Jude Watson, la autora de The Ties That Bind y The Death of Hope, no logró derribar una sociedad basada en la desigualdad y el desprecio de clase, así que las tensiones acumuladas serán el foco de un nuevo conflicto mortal. El destino de los mineros Bandomeer es aún peor. En el año 19 antes de la batalla de Yavin se atrevieron a levantarse contra sus amos, pero el propio Darth Vader encabezó la represión. Mal armados, mal equipados, los y las rebeldes fueron destrozadas por los stormtroopers encargados de hacer cumplir la ley de las compañías transgalácticas: nueva evidencia de la colusión entre el poder político y el capital denunciada por Mehrdad Vahabi en sus trabajos sobre el estado depredador. 


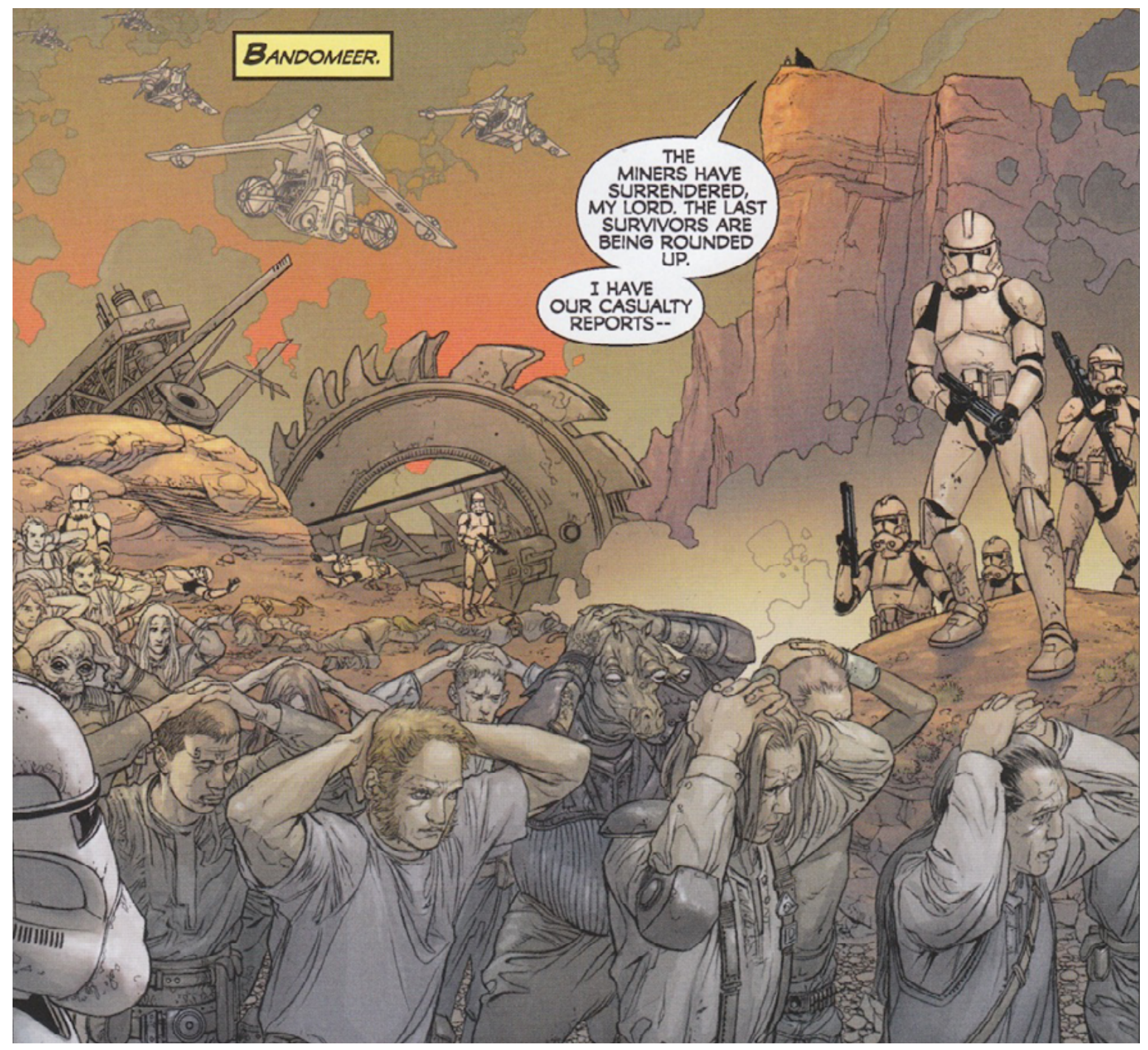

Figura 11. Después del aplastamiento de su revuelta, los mineros de Bandomeer, han sido deportados en campos de detención (Harrison, Wheatley, Chukry y Jackson, 2010).

No obstante, en Amanecer de los Jedi, Tim Lebbon nos recuerda la historia ejemplar del centro minero llamado "La locura de Dan" que sufrió una larga huelga salpicada de enfrentamientos violentos con la milicia pagada 
por los propietarios para restablecer el orden y la producción. A pesar de muchos sufrimientos, pérdidas y duelos, la tenacidad de los y las rebeldes, su espíritu de sacrificio y su capacidad organizativa les permitieron comprar la mina y luego convertirla en una cooperativa obrera. Esta victoria nos ofrece el derecho a esperar que la lucha contra el capitalismo transgaláctico no sea siempre condenada al fracaso. De hecho, no debemos olvidar que toda la saga Star Wars está ubicada bajo el signo de la esperanza, tal como le recordaba Jyn Erso en la película Rogue One a los pocos locos que aceptaron seguirla para robar los planes de la Estrella de la Muerte: "La esperanza es la base de todas las rebeliones". 8

Por consiguiente, no es de casualidad si, entre las muchas referencias a la cultura popular que han sido utilizadas últimamente por los y las protagonistas de las manifestaciones en contra del poder capitalista y neoliberal tanto en Chile como en Colombia (desde las máscaras de $V$ for Vendetta o de La casa de papel hasta los disfraces del Joker de Todd Philips), Star Wars haya jugado un papel destacado. Pudimos ver en las calles de Santiago a jóvenes activistas que gritaban "¡Chile despertó!” y exigían el fin de un sistema injusto asimilado al imperio galáctico refiriéndose a los personajes más destacados de la saga: maestro Yoda o la princesa Leia (figura 12). En Colombia, al frente de los desfiles organizados para el paro nacional del 4 de diciembre 2019, varios estudiantes de la Universidad Nacional, llevando cascos y máscaras para protegerse de los gases lacrimógenos, exhibían escudos de madera con el símbolo de la Alianza Rebelde en lugar de la hoz y el martillo de la generación anterior (figura 13). ¿Muerte o transfiguración de los imaginarios políticos? Pues, no importa: ¡Que la Fuerza los acompañe!

8 En la galaxia Star Wars, esta esperanza es sin embargo bastante ambigua porque una liberación política (triunfo final de la Rebelión sobre el imperio en El regreso del Jedi), no significa automáticamente una liberación social: con el regreso de la República las viejas estructuras de dominación económica siguen siendo vigentes con muy pocas alteraciones. 


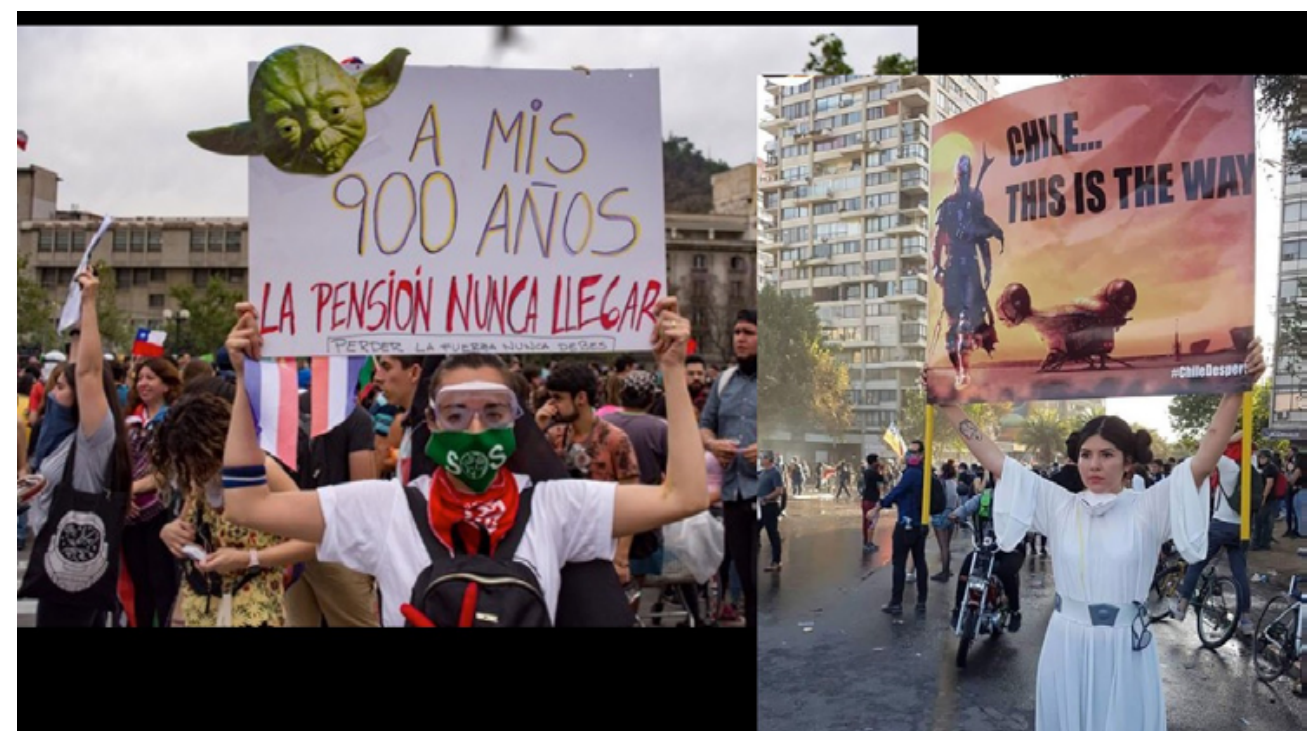

Figura 12. Yoda y Leia en Chile (fuente: Ricardo Greene y De Clod @muskhodee. (2019, november 28). https://bit.ly/2ZZTakk).

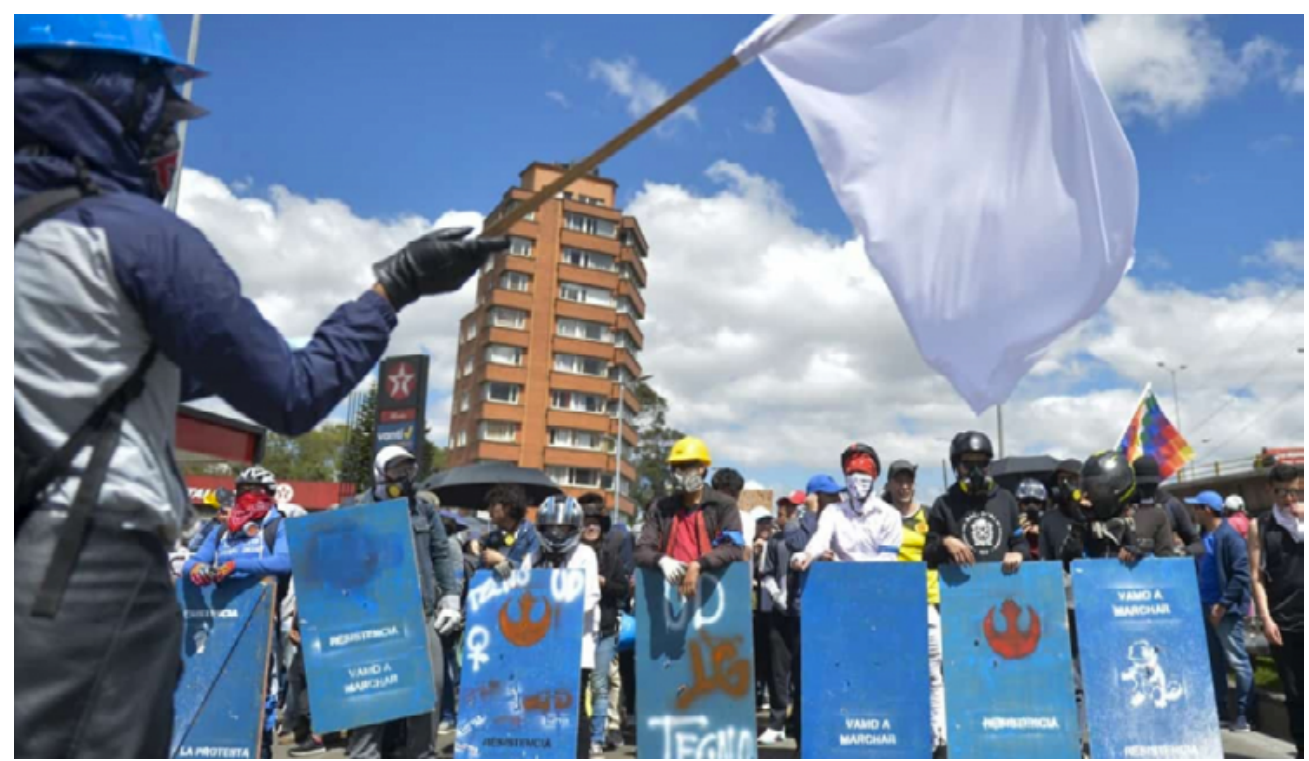

Figura 13. La Alianza rebelde en Colombia (Pulzo. (2019, December 4). Primera línea de defensa de la vida, la imagen que llamó la atención en marcha del 4D. https://bit.ly/32XFNTA). 


\section{REFERENCIAS}

Anderson K. J. y Moesta, R. (1999). Illusions de grandeur (Delusion of Grandeur). Paris: Pocket Junior.

Cleaver, T. (2011). Economics. The Basics. New York: Routledge.

Cocco, G. y Szaniecki, B. (dir.) (2015). Creative capitalism, Multitudinous Creativities: Radicalities and Alterities. Lanham-Maryland: Lexington Books.

Denning, T. (2015). L'Ultime épreuve (Crucible). Paris: Pocket.

Duggam G. y Noto, P. (2016). Chewbacca : Les mines d'Andelm. Nice: Panini Comics.

Engels, F. (1845). Situación de la clase obrera en Inglaterra. Digitalización: Por JOJ, 2002. Esta edición en PDF: Mayo 2019. https://bit. 1y/2ZZ3zwuFritel J. y Roche M. (Director). (2012), Goldman Sachs, la banque qui dirige le monde. Arte Thema. https://bit.ly/2CNbrsj

Gray, C. (2019). Maître \& apprenti (Master \& Apprentice). Paris: Pocket.

Harrison, M., Wheatley, D., Chukry, C. y Jackson, D. (2010). Star Wars: Dark Times. Blue Harvest, Part Three. Milwaukie: Dar Horse Comics.

Jaurès, J., "Discours du 7 mars 1895 à la Chambre des communes", dans Jean Jaurès : Textes choisis, Paris, Éd. Sociales, 1959, 88

Karpyshyn, D. (2008). La voie de la destruction (Path of Destruction). Paris: Fleuve Noir.

(2011). La dynastie du mal (Dynasty of Evil). Paris: Fleuve Noir.

Keyes, G. (2002). Renaissance (Rebirth). Paris : Fleuve Noir.

Kinsley, M. (2008). Creative Capitalism. A Conversation with Bill Gates, Warren Buffet and Other Economic Leaders. New York: Simon \& Schuster.

Kushins, J. (2016). The Art of Rogue One, A Star Wars Story. New York: Abrams.

Lebbon, T. (2015). L'Aube des Jedi (Dawn of the Jedi). Paris: Pocket. 
Luceno, J. (2001). L'éclipse des Jedi (Jedi Eclipse). Paris: Fleuve Noir. (2005). Labyrinth of Evil. New York: Ballantines Books. (2012). Darth Plagueis. New York: Arrow.

Musset, A. (2014, July). Des communautés mayas en lutte pour leurs terres. San Juan Saquatepéquez contre l'entreprise CEMPRO. Divergences 2, №39. https://bit.ly/32W9epg---. (2015, July). Projets hydroélectriques en terre maya : les communautés maya chor'Ti' en lutte. Divergences 2, $\mathrm{N}^{\circ}$ 42. https://bit.ly/3hydYW7.

Piketty, T. (2014). El capital en el siglo XXI. México: FCE. (2019). Capital e ideología. Barcelona: Deusto.

Reaves M. y Perry, S. (2005). Medstar 1: Chirurgiens de l'espace (Medstar 1: Battle Surgeons). Paris: Fleuve Noir.

Robespierre, M. de. (2012, April 24). Sur les principes de morale politique qui doivent guider la Convention nationale dans l'administration intérieure de la République. Le Grand Soir, Journal Militant d'Information Alternative. https://bit.ly/2WTHHkw.

Roche, M. (2011). La Banque. Comment Goldman Sachs dirige le monde. Paris: Points Documents.

Rucka, G. (2015). La cavale du contrebandier (Smuggler's Run). Paris: Pocket Jeunesse.

Sherman, D. y Cragg, D. (2006). L'épreuve du Jedi (Jedi Trial). Paris: Fleuve Noir.

Stackpole, M. (1998). I, Jedi. New York: Bantham.

Tyers, K. (2001). Point d'équilibre (Balance Point). Paris: Presses de la Cité.

Vahabi, M. (2016). The Political Economy of Predation. Manhunting and the Economics of Escape. Cambridge: Cambridge UP.

Watson, J. (2001a). Les liens les plus forts (The Ties That Bind). Paris: Pocket Junior. (2001b). La fin de l'espoir (The Death of Hope). Paris: Pocket Junior. (2002a). La marque royale (The Mark of the Crown). Paris: Pocket Junior. 
(2002b). La menace venue du passé (The Dark Rival). Paris: Pocket Junior. (2003a). Le jour du jugement (The Day of Reckoning). Paris: Pocket Junior. (2003b). Danger mortel (The Evil Experiment). Paris: Pocket Junior. Wheeler, A. (2016). Star Wars, Force Rebelle 1. La cible (Rebel Force 1. Target). Paris: Pocket Jeunesse.

Zahn, T. (2018). Star Wars: Thrawn. Paris: Pocket. 